\title{
USO DE IMÁGENES DE ARCHIVO EN PUBLICIDAD AUDIOVISUAL: ESTUDIO DE CASOS
}

\author{
Elena De-la-Cuadra-De-Colmenares, Iris López-De-Solís y María-Victoria \\ Nuño-Moral
}

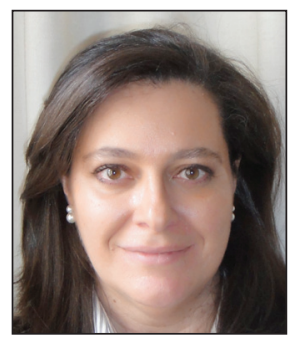

Elena De-la-Cuadra-De-Colmenares, licenciada en ciencias de la imagen y doctora en documentación, es profesora de la Universidad Complutense de Madrid desde 1997. Tras sus inicios en el mundo de la producción publicitaria, ha compaginado la docencia en varias universidades (UCAM, UC3M) con la producción cinematográfica y televisiva en varias productoras (Zoetrope Films, Film Potowsky, Ogro Films, Riot Cinema Collective, Grupo Ganga). Es autora del libro Documentación cinematográfica (Editorial UOC, 2013).

http://orcid.org/0000-0003-3057-2176

Univ. Complutense, Fac. de Ciencias de la Información, Sección de Biblioteconomía y Documentación Av. Complutense, s/n. 28040 Madrid, España ecuadra@ccinf.ucm.es

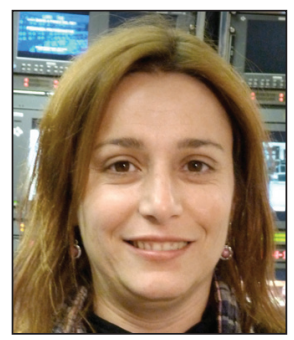

Iris López-De-Solís es licenciada en historia por la Universidad Complutense de Madrid (UCM), máster en información y documentación por la Universidad Carlos III de Madrid (UC3M) y DEA en documentación por la UCM donde actualmente lleva a cabo su tesis doctoral. Trabaja como documentalista en los Informativos de TVE en Madrid. Es docente en el Master de documentación audiovisual del IRTVE y la UC3M. Es autora de varias publicaciones sobre documentación audiovisual en cine y televisión, entre ellas el libro El film researcher (Editorial UOC, 2013).

http://orcid.org/0000-0003-0957-7474

Televisión Española (TVE). Torrespaña Alcalde Sáinz de Baranda, 92. 28007 Madrid, España iris.lopez@rtve.es

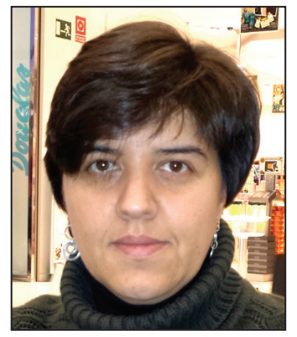

María-Victoria Nuño-Moral es profesora titular de la Facultad de Ciencias de la Documentación y la Comunicación de la Universidad de Extremadura, donde imparte docencia de documentación informativa y documentación audiovisual en los grados de información y documentación y de comunicación audiovisual. Autora de publicaciones, se ha especializado en la actividad documental desarrollada en el ámbito de los medios de comunicación, lo que la ha llevado a participar en cursos, congresos y proyectos de investigación.

http://orcid.org/0000-0002-5447-4813

Universidad de Extremadura, Facultad de Ciencias de la Documentación y la Comunicación Plazuela Ibn Marwan. 06071 Badajoz, España mvnunmor@alcazaba.unex.es

\section{Resumen}

La publicidad audiovisual emplea técnicas heredadas de productos audiovisuales previos, como el cine o la televisión. Entre esas técnicas encontramos un recurso que aporta un matiz especial a la breve historia narrada en un anuncio: el uso de imágenes de archivo. Se analizan varios casos para determinar los diferentes usos de las imágenes de archivo en la publicidad audiovisual, observando sus peculiaridades (de archivo real o simulado) y el resultado final del spot en que son insertadas.

\section{Palabras clave}

Publicidad televisiva, Televisión, Multimedia, Video, Anuncios, Utilización, Uso, Documentación audiovisual, Imágenes de archivo, Comunicación, Spots, Márqueting, Marcas comerciales.

\section{Title: Use of archival footage in audiovisual advertising: case studies}

\section{Abstract}

Audiovisual advertising tells short stories in a few seconds, using techniques inherited from cinema and television. A resource that gives a special tone or tint to the story is the use of archival images. Some cases are analyzed to describe the different uses of archival footage in audiovisual advertising. 


\section{Keywords}

Broadcast advertising, Advertisements, Multimedia, Ads, Video, Television, Use, Archival images, Archive, Communication, Marketing, Trademarks, Branding, Audiovisual documentation, Footage.

De-la-Cuadra-De-Colmenares, Elena; López-De-Solís, Iris; Nuño-Moral, María-Victoria (2014). “Uso de imágenes de archivo en publicidad audiovisual: estudio de casos". El profesional de la información, enero-febrero, v. 23, n. 1, pp. 26 -35.

http://dx.doi.org/10.3145/epi.2014.ene.03

\section{Introducción}

La actividad publicitaria es un proceso comunicativo basado en la difusión de mensajes con unos objetivos prefijados, utilizando para ello algún medio de difusión. En función del canal elegido se establecerán las características del mensaje transmitido y de la campaña publicitaria en su conjunto.

La televisión es uno de los principales escaparates para un gran número de publicistas. Según datos de la $A I M C^{1}$ la televisión es el medio de comunicación con mayor audiencia $(89,2 \%)$ frente a sus máximos competidores: la radio $(61,8 \%)$ o internet (50,7\%). La publicidad en televisión aprovecha los recursos propios del lenguaje audiovisual: montaje, ritmo, música, profundidad de campo, etc. $\mathrm{Y}$, como hemos estudiado en trabajos previos (De-la-Cuadra-De-Colmenares; López-De-Solís, 2012), uno de esos recursos aplicados a la narrativa audiovisual es la inserción de imágenes de archivo.

A raíz de lo expuesto, el objetivo principal del presente trabajo es determinar el uso de las imágenes de archivo en la publicidad audiovisual haciendo especial hincapié en el ámbito televisivo. Ahondar en la finalidad, intencionalidad y efectos que el uso de dichas imágenes dentro del spot publicitario tiene en el espectador/consumidor son los pilares sobre los que se sustenta la presente investigación.

Los usos de material de archivo en productos de ficción son muy diversos, y cada uno de ellos despierta una sensación diferente en el espectador. El recurso de insertar imágenes antiguas (o que lo parecen) dotan al film de un barniz de verosimilitud deseado en la coherencia narrativa de algunas obras.

\section{La publicidad en televisión}

Resulta difícil localizar o establecer una definición unánime sobre el concepto de publicidad, aunque todas sitúan como eje central la comunicación. La publicidad se muestra como una herramienta de comunicación más a la hora de transmitir un determinado tipo de mensajes: los anuncios.

La comunicación publicitaria se fundamenta en tres pilares:

- informar: proceso comunicativo o de adquisición de conocimientos;

- convencer: comunicación persuasiva sobre el comportamiento o actitud de la persona;

- recordar: transmitir la necesidad de tener el producto o servicio que se ofrece.

Siguiendo a García-Uceda (2000), "informamos de todo aquello del producto que pueda interesar al receptor, para que adopte la decisión de adquirirlo. Convertimos la infor- mación en un argumento de persuasión". No obstante, desde la perspectiva de los mass media, el componente persuasivo está por encima del comercial.

Según David Ogilvy (1990), lo que hay que resaltar en un anuncio es lo más significativo, de manera que sea recordado por ello. Esto contribuye a crear tanto la "imagen del producto", aspecto quizás más ligado a la actividad de marketing, y la "imagen de la marca". Al anunciante le interesa saber el lugar que ocupa su marca respecto a aquellas de la competencia. A este hecho se le denomina "posicionamiento": intentar que la marca sea la más conocida del mercado.

Ahora bien, en el caso de la televisión, ¿qué características ha de adoptar dicho mensaje?; ¿cómo ha de presentarse y qué ha de contener un anuncio?

La comunicación publicitaria se fundamenta en tres pilares: informar, convencer y recordar

La televisión, como medio publicitario, ofrece una serie de puntos fuertes que hacen que siga siendo el canal mayoritariamente elegido. Entre ellos, cabe destacar que el carácter audiovisual conlleva un aumento de las opciones de comunicación y expresión, inexistentes en los otros medios tradicionales y, consecuentemente, incrementa el perfil persuasivo de sus mensajes.

Las imágenes adoptan el papel principal dentro del spot televisivo dado que, junto con la función informativa, ejercen una función de reclamo y de recordatorio. De ahí la necesidad de pensar y determinar de manera acertada y eficaz el tipo de imagen/es y de qué manera se va a utilizar en el anuncio. En suma, las imágenes vienen a complementar el proceso comunicativo-publicitario.

García-Reyes (2003) afirma en su tesis doctoral que la publicidad ha adoptado estas funciones:

- referencial: la imagen y el texto se identifican con el producto o servicio ofertado, sustituyéndolo o representándolo;

- apelativa o connotativa: la más importante, trata de persuadir a los receptores;

- poética: cuando la imagen y el texto dramatizan, de manera emotiva, el bien publicitado;

- conativa o que intenta influir en la conducta del receptor: todos los elementos presentes en el mensaje publicitario se dirigen directamente al espectador, de tal manera que 
éste se implica en mayor medida con el contenido del anuncio.

El uso de archivo, como veremos, aumenta el alcance sugestivo de la marca. Atendiendo a las funciones arriba descritas, observamos que la inclusión de archivo acrecienta dos de ellas: la poética y la conativa. Podemos incluso añadir una función que cumplen los anuncios con imágenes de archivo: dado que dichas imágenes otorgan al spot un barniz histórico y de prestigio de la marca, podríamos llamarla función épica ${ }^{2}$.

También González-López (2002) propone en su tesis doctoral un modelo para analizar spots, en el que debemos atender a cuatro variables:

- sistema de mercadeo: segmentación, alcance y frecuencia;

- variable tecnológica: formato y estructura, entre otras;

- variable técnica-objetiva: aspecto del mensaje: forma, expresión, código;

- variable subjetiva: valores, recepción.

Dentro de la variable técnico-objetiva señala dos posibles estructuras narrativas: discurso o relato, y dentro del relato, emotivo o histórico. Las imágenes de archivo refuerzan extraordinariamente esta estructura narrativa histórica.

El uso de archivo aumenta el alcance sugestivo de la marca

\section{Metodología}

Se ha utilizado el método de investigación empírica denominado "estudio de casos" (Yin, 1999; Muñoz-Serván; MuñozServán, 2001; Stake, 2005; Martínez-Carazo, 2006). Según Yin (1999) se utiliza para dar respuesta a los interrogantes de tipo "cómo" y "por qué" dentro del estudio de entidades ubicadas en un marco contextual de la realidad. Se refuerza así el carácter explicativo frente al exploratorio o descriptivo descrito por el mismo autor. En palabras de Stake (2005), "estudiamos un caso cuando tiene un interés en sí mismo. Buscamos el detalle de la interacción con sus contextos".

En la presente investigación, el interés no reside en los ejemplos escogidos para el análisis sino en los porqués que se derivan del uso realizado sobre el tipo de información que encontramos en ellos. Con ello se consigue contextualizar la actividad publicitaria en televisión.

Se trata pues, en palabras de Yin, de una estrategia de diseño de estudio de casos múltiple, cuyo elemento de análisis es el conjunto de casos únicos (cada uno de los spots analizados). Con ello, se obtendrá lo que el mismo autor denomina "generalización analítica"; es decir, cada análisis particular se integrará dentro de un contexto más amplio, donde algunos resultados podrán ser compartidos con otros similares.

La técnica de investigación relacionada con el método escogido es el análisis de contenido. En este caso, ha consistido en el análisis detallado del contenido de los spots que han formado parte de la muestra seleccionada para su análisis.
El estudio tuvo lugar entre los meses de mayo y agosto de 2013.

\section{Anuncios analizados}

El origen de esta investigación parte de la observación de la programación de las cadenas generalistas en España. El natural interés de las autoras por los productos audiovisuales se acrecienta en el caso de la publicidad con imágenes de archivo, dado que es una técnica peculiar de crear el mensaje promocional, apelando a sentimientos y recuerdos de la marca anunciante o de la vida del público y potencial consumidor. La observación de este tipo de publicidad dio paso al análisis del mensaje, y se observaron diferentes usos y técnicas de inserción o de grabación de este tipo de imágenes.

Entre los anuncios susceptibles de ser analizados, la muestra se centra en los que claramente reflejan el fenómeno estudiado para, como se ha explicado en el apartado de metodología, poder llegar a unas conclusiones, partiendo del estudio de casos significativos y representativos.

Los spots elegidos, vistos en España en cadenas generalistas, son:

\section{- Estrella Damm: Pasado y presente http://www.youtube.com/watch?v=AravxmqeOs4}

Con la pantalla dividida en dos, este anuncio muestra paralelamente acciones alejadas en el tiempo: se muestra cómo las vivencias y experiencias relacionadas con esta cerveza no han variado con el paso de los años, manteniendo la tradición. En el lado izquierdo de la pantalla se narra cómo era la vida en el pasado, y en el lado derecho se describen las mismas situaciones en la actualidad.

- Citroën DS3: Antiretro. Marilyn Monroe y John Lennon Canal oficial YouTube Citroën: http://www.youtube.com/watch?v=8JcV6bLhE_I

Paradójica utilización de unas imágenes de archivo en blanco y negro de unas declaraciones de Marilyn Monroe en la que rechaza vivir en el pasado y en la nostalgia, o de John Lennon criticando la vuelta a los 60 .

\section{- BMW X3: Be water http://www.youtube.com/watch?v=SV1uvFI6AKU}

Imágenes de archivo en blanco y negro en las que podemos ver un primer plano del actor y artista marcial Bruce Lee actuando como filósofo, aconsejando a la audiencia ser maleable como el agua, con la frase: "Be water, my friend".

\section{- 90 años de Citroën} http://www.youtube.com/watch?v=Grg/NFDLMnQ

A través de imágenes de archivo (entre ellas, spots de antiguos modelos de Citroën), se recuerda la historia y la evolución de la marca e incluso algunas personalidades que han utilizado un Citroën, como el Papa Juan Pablo II. Las imágenes de archivo se intercalan con imágenes de la fabricación de modelos actuales.

\section{- Banco Santander y Ferrari: Historias paralelas http://www.youtube.com/watch?v=PRjry4bH5PQ}

Anuncio emitido cuando el Banco Santander se convirtió en el principal patrocinador de la escudería Ferrari en F1, 
en el que se recuerda la historia de ambos simultáneamente: marcas unidas, según el spot, por unos mismos valores.

- Coca-Cola: 125 años de historia Canal oficial YouTube Coca-Cola: http://www.youtube.com/watch?v=0xfVvgiuPCU

En 2011 Coca-Cola celebró sus 125 años de historia. Con este anuncio se recuerdan los grandes acontecimientos históricos, deportivos, sociales y económicos ocurridos en el mundo desde 1886.

- Coca-Cola: Razones para creer Canal oficial YouTube Coca-Cola: http://www.youtube.com/watch?v=HBhw-19s9E8

Anuncio destinado a llegar a las emociones de los espectadores en tiempos de crisis. Utilizando imágenes actuales y algunas de archivo, la marca intenta contrarrestar las malas situaciones con acciones y actitudes positivas.

- Orlando: Recuerdos de la historia Canal oficial YouTube Orlando: http://www.youtube.com/watch?v=tpyX7z2_T10\#t=12

Un niño, que luego pasa a ser un adolescente y posteriormente un adulto, narra la evolución de su vida en el salón de su casa, siempre con tomate Orlando en la mesa.

- Generali Seguros: Vínculos Canal oficial YouTube Bassat Ogilvy: http://www.youtube.com/watch?v=ngkAleuc-YO

Con imágenes que parecen tomadas con una vieja cámara súper-8 de los años 60 , se narra la vida de un niño en su evolución hasta que se hace un hombre, junto a un león.

- Renault Koleos: Espíritu 4x4 http://www.youtube.com/watch?v=yMGpooDZA3s

Anuncio de lanzamiento del Renault Koleos, en el cual se incluyen imágenes de antiguos modelos de la marca (Renault 4 , Renault 5, y otros) utilizados como $4 \times 4$.

- Renault Mégane: Leyendas jóvenes http://www.youtube.com/watch?v=17H6UGmGBSM Imágenes de archivo de personajes conocidos (Bruce Lee, Salvador Dalí, Steffi Graf o Carl Lewis).

- ONCE: Sigmund Freud

Canal oficial YouTube Bassat Ogilvy:

http://www.youtube.com/watch?v=cLZe7M_8DPk

Imágenes de archivo de Sigmund Freud, acompañadas por un narrador que relata una anécdota de una entrevista al científico.

En el proceso de búsqueda de spots, encontramos más anuncios no emitidos en España, pero interesantes por el matiz que aportan a este estudio, como se verá posteriormente:

- Mercedes Benz: Inventions http://www.youtube.com/watch?v=zv0ZPyj7S6M

Repaso a todas las innovaciones y creaciones de Mercedes Benz en materia de seguridad con imágenes de archivo de sus pruebas.

- Save the children: No child born to die Canal oficial de Save the children UK:

\section{http://www.youtube.com/watch?v=Jn9oMA1GQ5Q}

Spot en el que varios niños del tercer mundo quedan asombrados ante imágenes de archivo de personalidades de la cultura, la sociedad o el deporte (Los Beatles, Mandela o Usain Bolt).

- Virgin Trains: Return of the train http://www.youtube.com/watch?v=1LeCSBfMAJk

Estrellas del cine como Gary Grant, John Mills, Albert Finney o Jack Lemmon aparecen en diferentes películas en las que el tren es el protagonista. Se utilizan fragmentos de films tales como Con la muerte en los talones o Con faldas y a lo loco.

- EDF Energy y Team Green Britain: Green Britain day Canal oficial de YouTube de Londres 2012 http://www.youtube.com/watch?v=p0G19R0k3UU

Anuncio en el que se promocionan los Juegos Olímpicos de Londres 2012 a través de imágenes de archivo de los juegos celebrados en esa ciudad en 1948. Simultáneamente se promueve la lucha contra el cambio climático.

- Witness: 20 Aniversario

Página oficial de Witness

http://www.witness.org/videos/20th-anniversary

A través de un recopilatorio de imágenes de archivo, se recuerdan aquellos momentos de conflictividad, lucha e injusticias en las que ha estado presente esta organización internacional.

El mensaje publicitario queda reforzado con la inclusión de imágenes de archivo

\section{Análisis de los spots}

\subsection{Usos del archivo}

Al analizar los anuncios mencionados se observa que el material de archivo se emplea de maneras muy diversas:

- se utiliza "puro", sin ningún tipo de modificación;

- se modifica alguna de sus facetas (audio o vídeo);

- se inserta a una persona no existente en las imágenes históricas (el llamado "efecto Forrest Gump");

- se extraen componentes de un archivo audiovisual histórico y se suman al material rodado en la actualidad, etc.

En los spots analizados se utilizan varias modalidades, que a continuación detallamos. En todas ellas observamos la función poética y la función épica; en algunos se observa además la función conativa, cuando el audio (modificado) interpela directamente al espectador.

Los usos encontrados, que a continuación se explican detalladamente, son los siguientes:

- Falso archivo

- Archivo

- Efecto Forrest Gump

- Archivo en la televisión de los protagonistas

- Archivo de antiguos anuncios de la propia marca

- Imágenes de prensa

- Archivo privado 
A continuación explicaremos cada uno de estos usos, con un frame de cada spot.

\subsection{Estudio de casos}

\subsubsection{Falso archivo}

Es la técnica de introducir en el anuncio imágenes que "parecen" antiguas: simulan ser imágenes rodadas hace años en cine, rescatadas para ese spot. Para acentuar la sensación de película antigua, se utilizan unos filtros digitales que imitan el deterioro que habitualmente presenta el cine antiguo: arañazos, saltos en el metraje, etc.

En ocasiones es imposible diferenciar si es falso archivo o archivo real. En el caso de que exista el making of, podemos ver el rodaje del spot y averiguar si el archivo es real o fingido. Si no existe este documento, podemos fijarnos en los aspectos técnicos, algo que sólo podría distinguir el ojo profesional de un cineasta: cómo se mueve la cámara, el tipo de plano, la iluminación...

Las razones por las que se emplea esta técnica son varias. Como hemos mencionado en las funciones, estas imágenes cumplen la función épica: narran y muestran los hitos de la marca para dotar a la misma de un aura de prestigio. También acentúan la función poética.

Dentro de este uso de falso archivo encontramos dos modalidades: cuando el archivo está "disfrazado" o cuando es "evidente". El disfrazado es material que se ha rodado ex profeso para ese spot, y luego se han aplicado filtros para simular material antiguo. El segundo es el que tiene esos mismos filtros y parece ser material de archivo, pero es evidente que no es cine antiguo por diversos factores, entre ellos la aparición en las imágenes de algo que rompe el hechizo (la marca, un objeto, el doblaje, etc.)

\subsubsection{Falso archivo disfrazado}

Encontramos varios ejemplos de este uso: Historias paralelas del Banco Santander, Espíritu 4x4 de Renault Koleos y 125 años de historia de Coca-Cola.

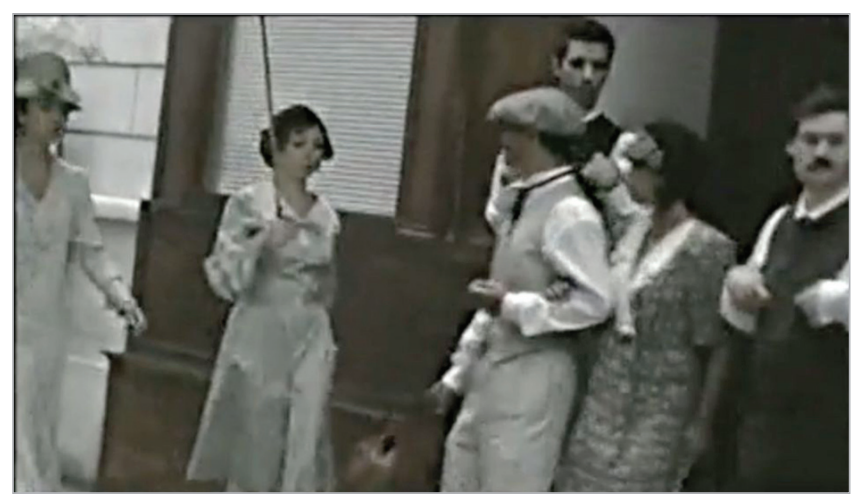

\section{Historias paralelas}

Parecen imágenes de principios del XIX, gente caminando por las calles de Santander. La posición de la cámara y la textura de las imágenes indican que no son antiguas.

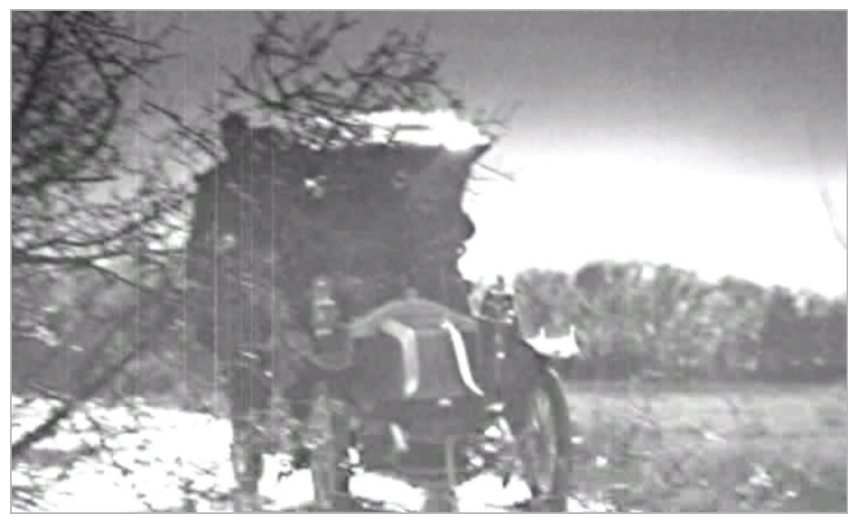

\section{Espíritu $4 \times 4$}

Los efectos digitales están muy cuidados, y solo el making of permite saber que no son imágenes de época.

\subsubsection{Falso archivo evidente}

Los spots que ilustran esta técnica son Vínculos, de Generali Seguros, y Recuerdos de la historia, de Orlando.

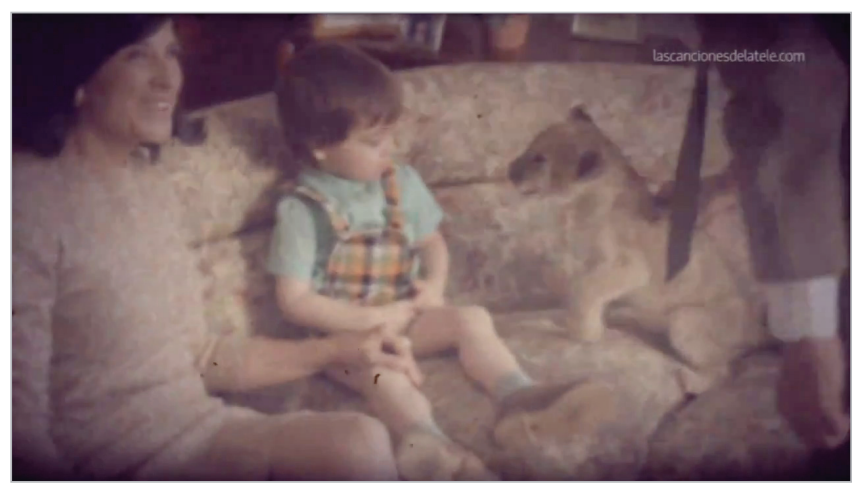

Vínculos

La presencia del león, símbolo de la compañía, demuestra de un modo evidente que no es archivo.

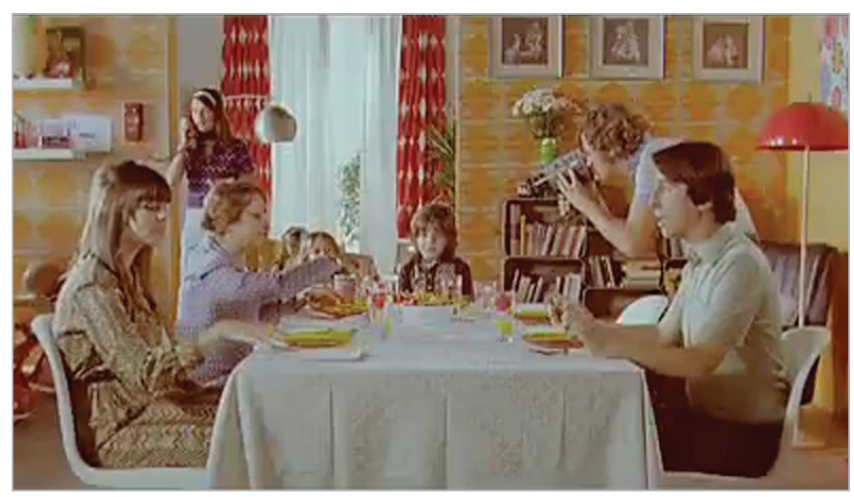

Recuerdos de la historia

Desde el principio el niño habla a cámara, y el doblaje es de un adulto. Las imágenes recrean los años 60 y 70, pero en ningún momento pretenden ser archivo. 


\subsubsection{Archivo}

Este sería el caso "puro": cuando se insertan auténticas imágenes de archivo, rescatadas para ilustrar el mensaje deseado por la empresa anunciante.

Antes de adentrarnos en esta categoría, debemos recordar que el término imágenes de archivo crea una falsa sensación de imágenes antiguas. Y no son sinónimos. Muchas imágenes pueden ser imágenes de archivo, sin tener que ser necesariamente ni antiguas, ni cargadas de un gran valor informativo, histórico o periodístico (por ejemplo, una fábrica actual).

Dentro de esta categoría, se puede establecer una subdivisión en función de dos aspectos diferentes: el contenido temático del archivo o el audio que lo acompaña.

a) Según el contenido temático del archivo:

- Archivo generalista: cuando se insertan imágenes de archivo de cualquier temática, con cualquier intención, por ejemplo, cómica, humanitaria, etc. (Save the children).

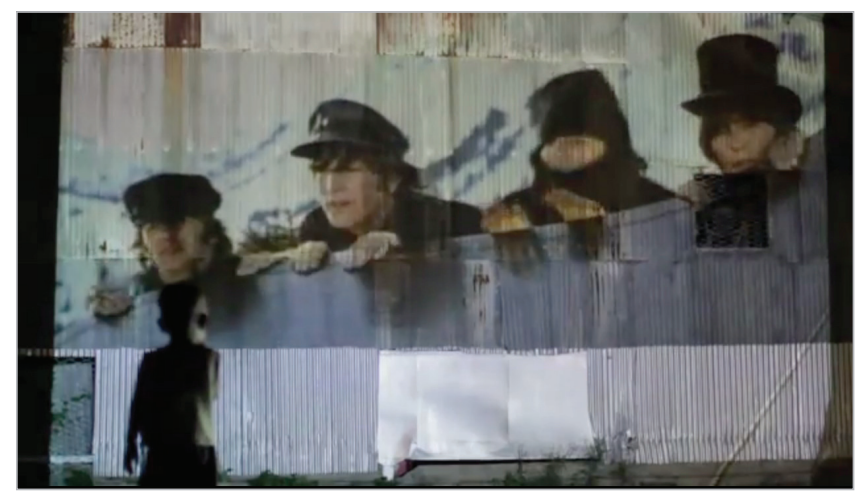

No child born to die

Archivo generalista: imágenes de varias épocas con personajes que han triunfado en diversos ámbitos. Un niño contempla un vídeo de Los Beatles.

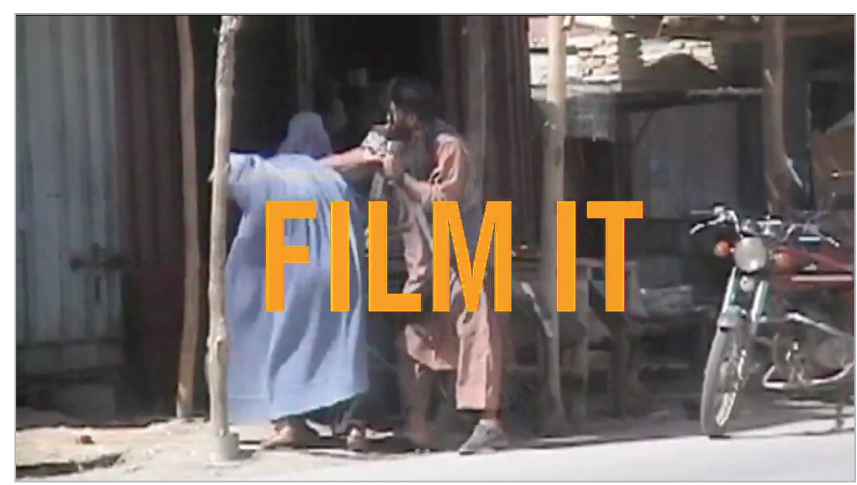

\section{Aniversario de Witness}

Archivo denuncia: la ONG Witness denuncia los atropellos a los derechos humanos gracias a los vídeos de sus afiliados, documentos que se muestran en el spot.
- Archivo temático: cuando las imágenes de archivo se refieren a un mismo tema hay una unidad temática común en el spot (Londres).

- Archivo denuncia: cuando las imágenes están seleccionadas para mostrar al espectador un determinado hecho contra el que la empresa anunciante quiere luchar (ONG Witness).

- Informativos: un presentador de informativos imprime a las imágenes un carácter de urgencia, de actualidad, de flash informativo (Coca-Cola).

b) Según el audio:

- Audio eliminado: el audio original desaparece sustituido por una locución o una melodía (90 años de Citroën).

- Audio falso: cuando se dobla a los protagonistas con un nuevo texto que apoya el mensaje deseado por la marca (Citroën DS3).

- Audio forzado: Se añade un componente auditivo que no existía previamente, para reforzar la sensación de documento histórico (ONCE).

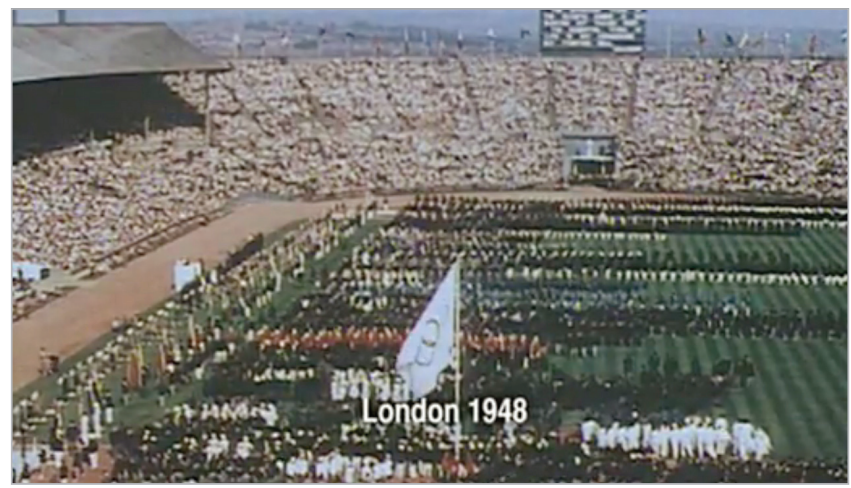

Londres 2012

Unidad temática: imágenes de los Juegos Olímpicos de Londres en 1948 para concienciar sobre unos JJOO de Londres 2012 ecológicos.

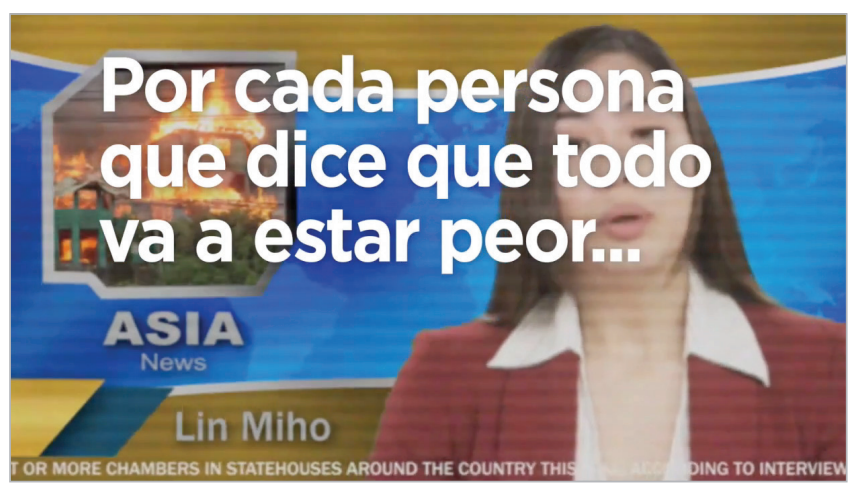

Razones para creer

Imágenes de informativos, alteradas digitalmente para que se perciba la textura de televisión. 


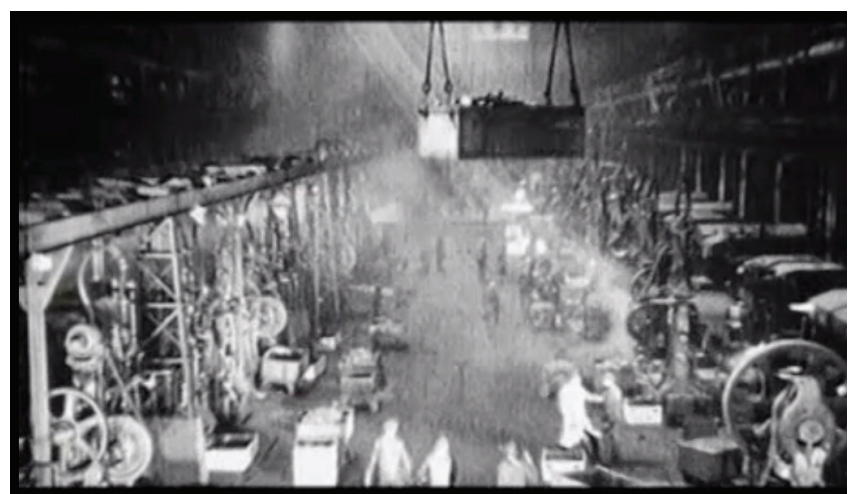

90 años de Citroën

Audio eliminado: se suceden imágenes de archivo de la marca. El audio es una rítmica canción que refuerza el montaje.

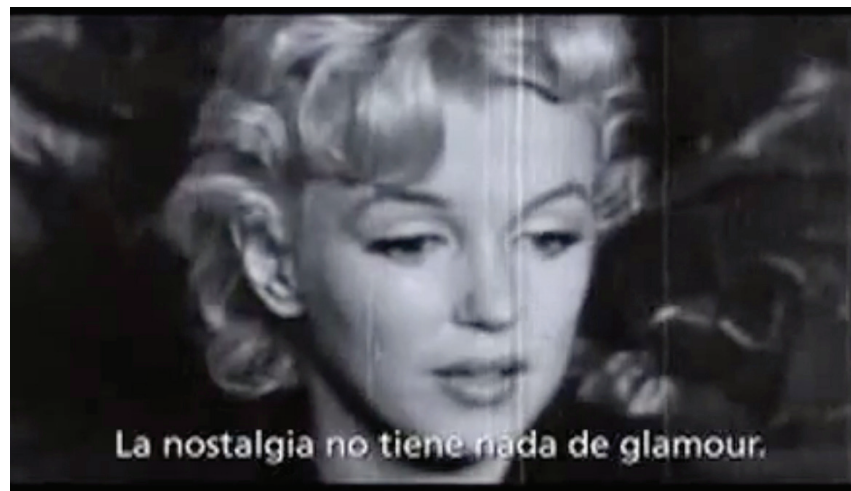

AntiRetro

Audio falso: caso extremo de doblaje falso: imitando la voz de los protagonistas, los famosos parecen estar censurando que la gente sólo mire al pasado y no invente cosas nuevas.

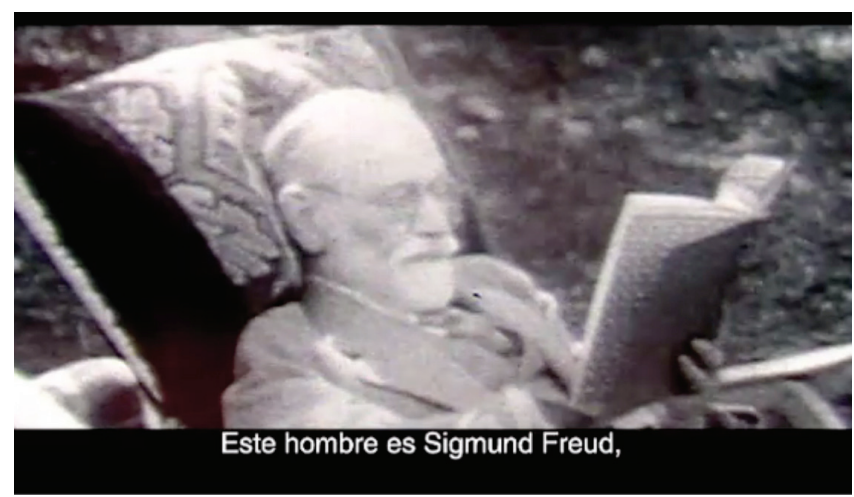

Sigmund Freud

Audio forzado: para reforzar en el espectador la sensación de cine mudo, se añade un efecto sonoro que imita el ruido de las antiguas cámaras de súper 8.

Un caso muy recordado en España fue el de la campaña de $B M W$ para lanzar su vehículo $B M W X 3$. En este spot aparecía el actor Bruce Lee hablando de la condición humana, y cómo deberíamos ser como el agua, que se adapta a su entorno. La famosa frase "Be water, my friend" se oyó entre los aficionados a la televisión y la publicidad.

Si embargo, poca gente conoce la realidad de este discurso. No es una frase original de Bruce Lee, sino una línea del guión de un episodio de la serie Longstreet, en la que el propio Lee interpretaba a un entrenador de artes marciales. Posteriormente le preguntan en una entrevista por ese texto. Finalmente $B M W$ extrae un fragmento de la entrevista para el spot.

http://www.youtube.com/watch?v=bsavc5/9QR4

http://www.youtube.com/watch?v=3MUoXOFq6dY

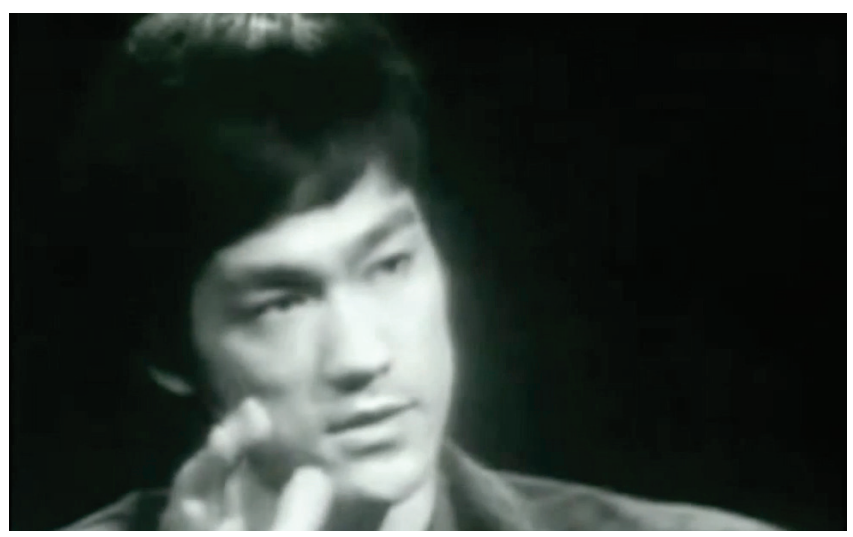

Be water

\subsubsection{Efecto Forrest Gump}

Entre los profesionales del cine y la televisión se llama efecto Forrest Gump a la manipulación de imágenes de archivo para insertar a un actor (o a un objeto) rodado en la actualidad, y hacer que interactúe con dichas imágenes. En la película que le da nombre, Tom Hanks parece estrechar la mano de Kennedy.

En estas líneas describimos dos tipos diferentes de este efecto, a los que hemos denominado "tradicional" e "inverso". En el tradicional la manipulación es como en la película Forrest Gump (Mercedes Benz: Inventions); el inverso consiste en extraer la figura humana del metraje de archivo (en el caso seleccionado para ilustrar este ejemplo, el spot de Virgin Trains) e insertarlas en material filmado hoy en día.

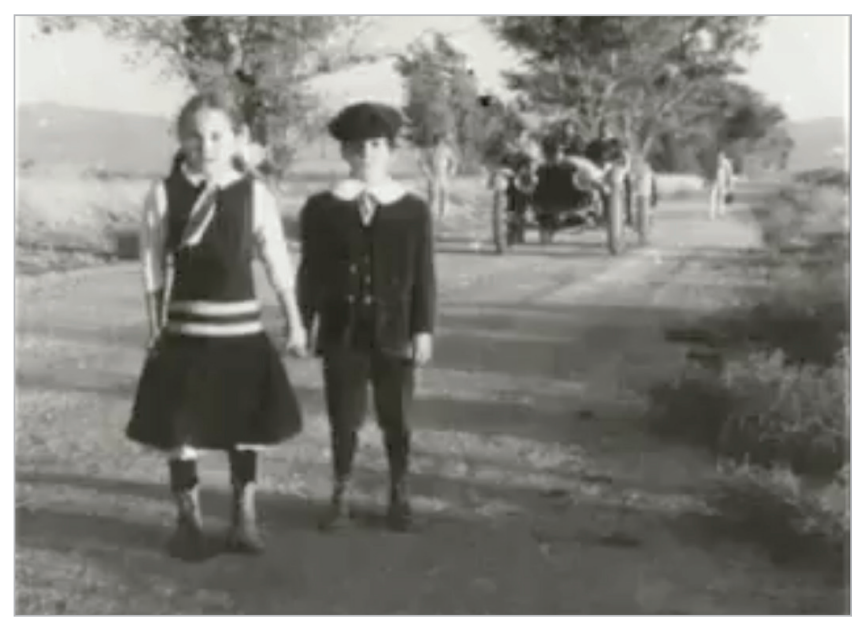

Inventions

Se inserta la figura humana en imágenes de pruebas a diferentes coches a lo largo del tiempo. Los actores, caracterizados y vestidos como en la época de la prueba correspondiente, se reúnen al final del anuncio, cada uno con el color con que aparecieron en el efecto Forrest Gump. 


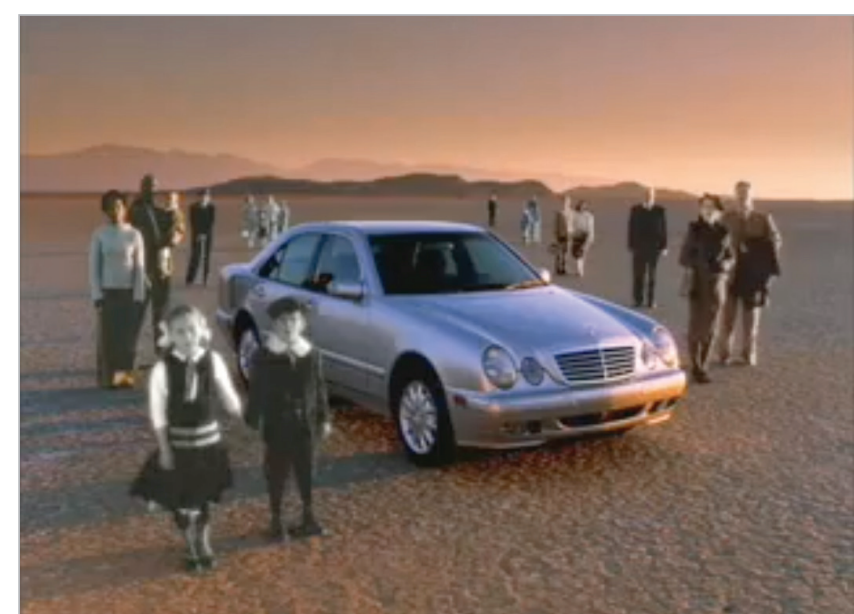

Inventions
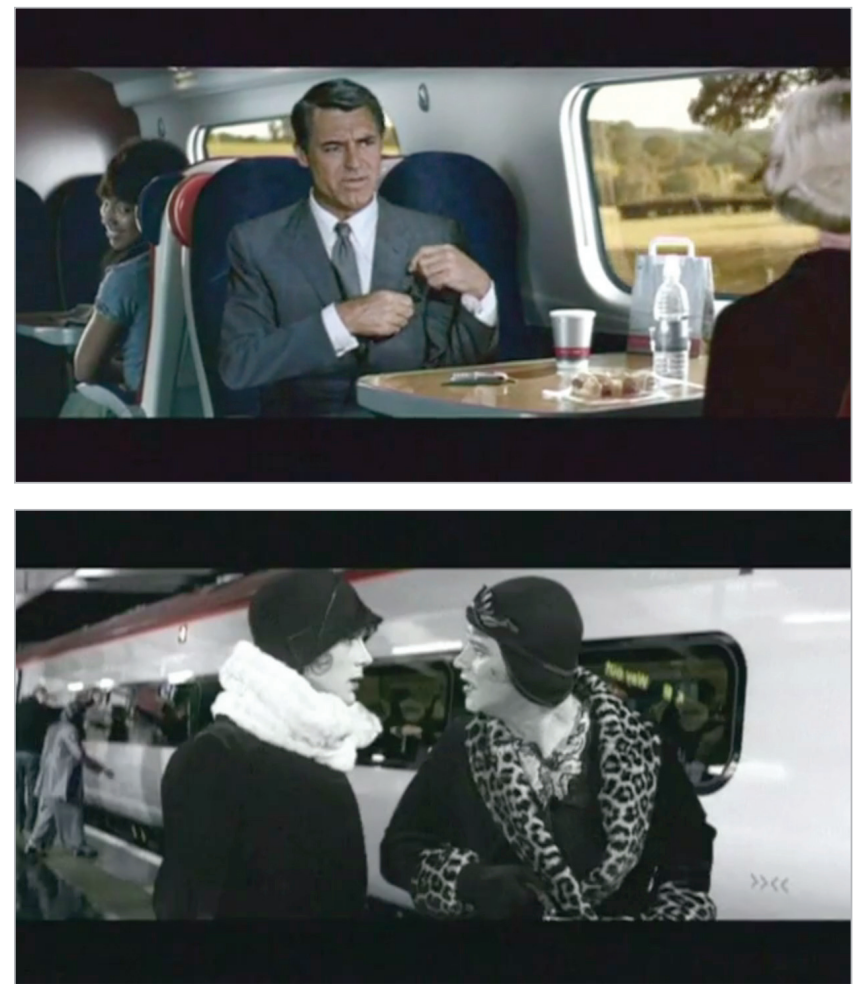

Return of the train

Personajes de diferentes películas son separados de su film original e insertados en los nuevos trenes de la marca, ante el asombro de los usuarios modernos.

\subsubsection{Archivo en la televisión de los protagonistas}

Una forma sutil de mostrar la marca anunciante es que aparezca en el anuncio en diferentes soportes o con forma de distintos mensajes icónicos. Aunque el espectador no lo perciba como parte central del mensaje publicitario, su ojo sí está viendo el logotipo o el color de la marca, y el cerebro lo procesa en un segundo plano. Es lo que los profanos Ilaman "publicidad subliminal", aunque no sea tal: es, concretamente, "publicidad sugestiva". No es subliminal (técnica prohibida en España ${ }^{3}$ ), puesto que nuestros sentidos lo perciben en un umbral de percepción normal, pero sí es un mensaje secundario.

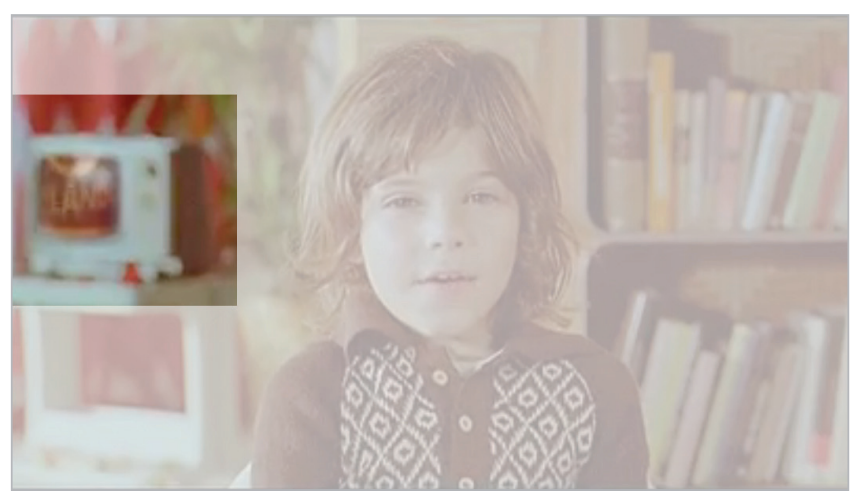

Recuerdos de la historia

El televisor del salón del niño-narrador muestra diferentes anuncios de la marca anunciante.

\subsubsection{Archivo de anuncios propios}

Algunos anuncios se crean para celebrar un aniversario de la marca. Cuando una marca puede celebrar que sigue presente en los hogares durante, por ejemplo, 100 años, en ocasiones realiza un spot con fragmentos de otros anuncios recordados por la audiencia.

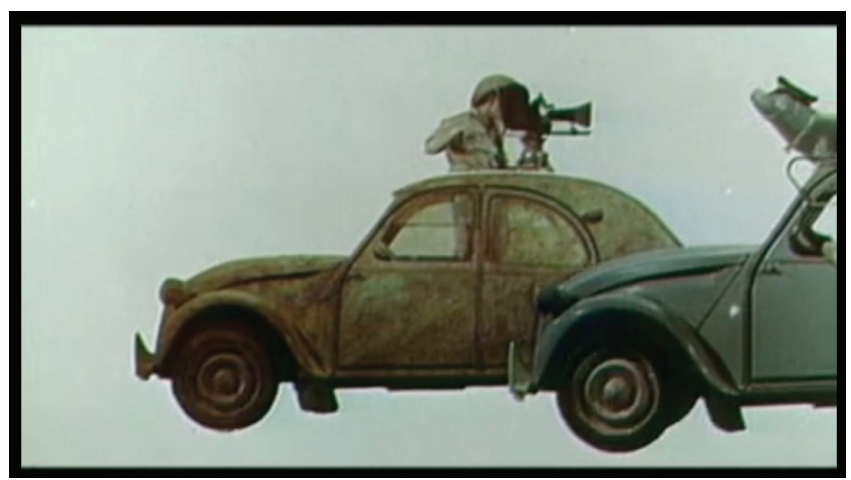

90 años de Citroën

En este spot se mezclan fragmentos de anuncios de años pasados.

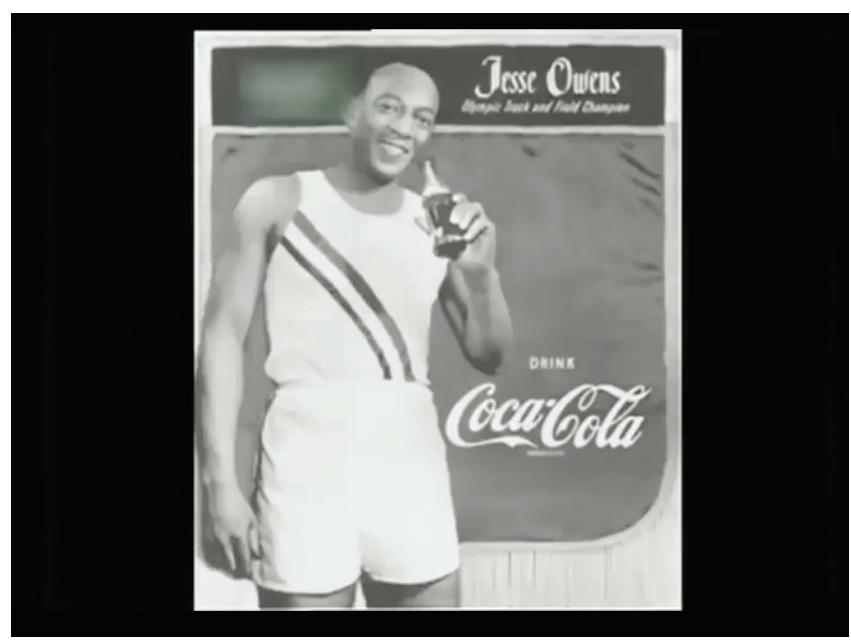

125 años de Coca-Cola

Páginas de prensa con publicidad de este refresco insertadas en el montaje. 
También se han detectado dos categorías en este uso:

- Publicidad audiovisual: se aprovechan spots de años anteriores, y se unen los momentos más recordados de cada anuncio.

- Publicidad estática: como si se tratara de una investigación en la que se recurre a la hemeroteca, la empresa anunciante muestra páginas de periódicos antiguos en las que insertó publicidad.

\subsubsection{Imágenes de prensa}

Las portadas de los periódicos diarios son un recurso empleado por el cine y la publicidad. Cuando aparecen imágenes de periódicos en el cine suele ser para reflejar un gran acontecimiento, y quizá podemos ver la portada del diario girando hasta que queda fija en pantalla con el gran titular. En publicidad es poco habitual, pero se han hallado ejemplos en la publicidad de Coca-Cola, en el anuncio de sus 125 años.
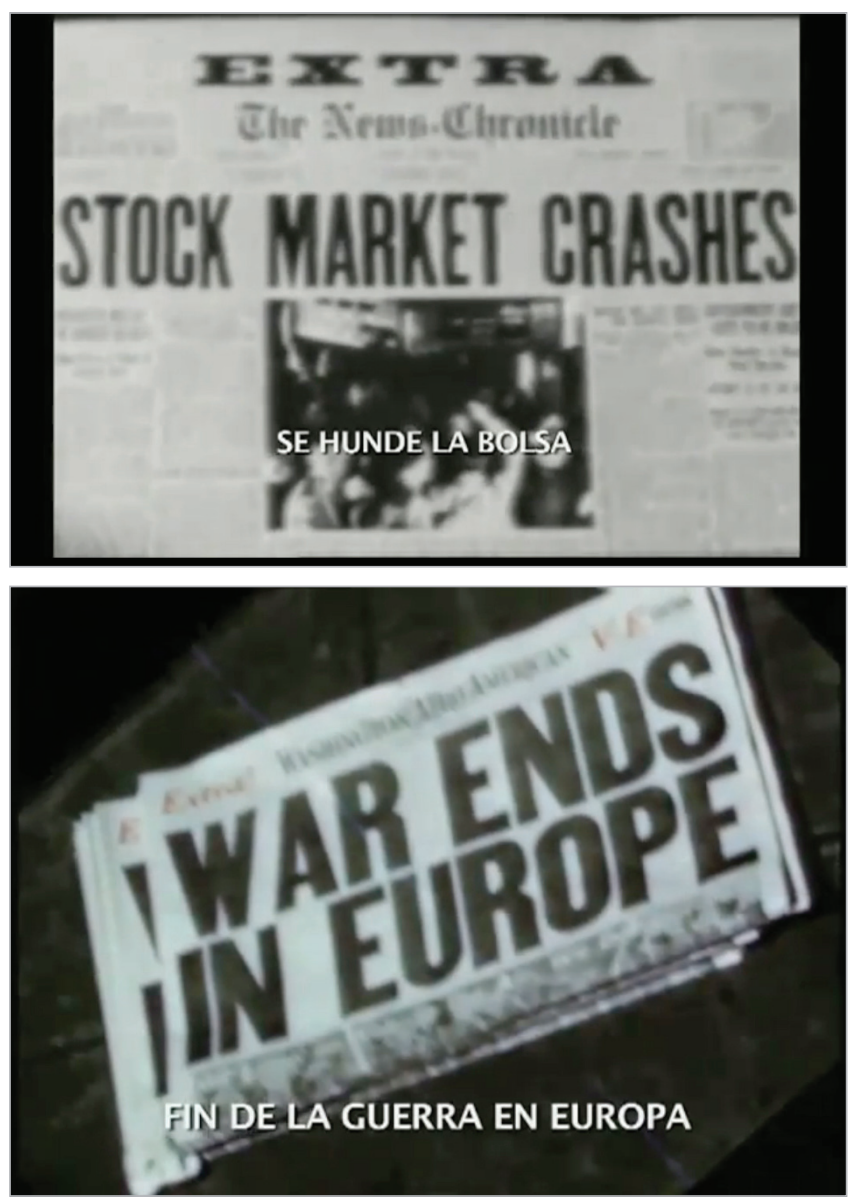

125 aniversario de Coca-Cola

\subsubsection{Archivo privado}

En ocasiones, la compañía que desea realizar un spot impactante, recurre a los archivos personales de personas anónimas o de personajes famosos. Esto es imposible de detectar por el espectador si no recibe información complementaria: un making of o un artículo que nos detalle de dónde provienen las imágenes. Es el caso del anuncio del Renault Mégane: un artículo en la web de TVanuncios ${ }^{4}$ nos descubre la procedencia de las imágenes de Steffi Graf.

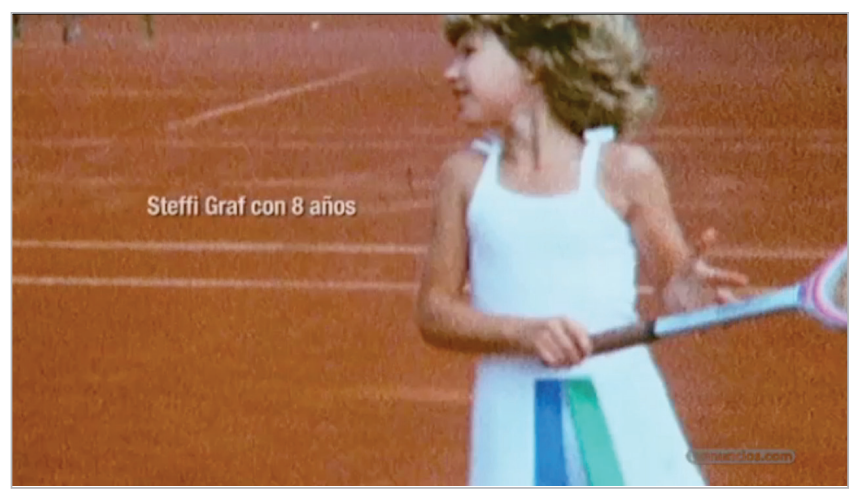

Leyendas jóvenes

Imágenes de Steffi Graf inéditas, provenientes del archivo familiar.

\section{Conclusiones}

El mensaje publicitario queda reforzado con la inclusión de imágenes de archivo. Es un modo de mostrar al espectador la longevidad de la marca, su gran aceptación a lo largo del tiempo entre los consumidores. Las imágenes refuerzan lo que hemos dado en llamar "función épica": muestra los propios logros, los hitos de la marca a lo largo de la historia con testigos audiovisuales. Las imágenes antiguas cumplen también la función poética, ya que apelan a los sentimientos del espectador. Esta función se incrementa con el audio: suaves melodías si se busca sentimentalismo, melodías pegadizas si se busca un carácter lúdico, o falso audio si se quiere agudizar la función conativa.

No siempre las imágenes que parecen ser antiguas lo son realmente. Las tecnologías digitales permiten ensuciar las imágenes rodadas para que parezcan sacadas de un archivo antiguo. Los filtros que se aplican imitan el aspecto que tiene una película química con el paso del tiempo, especialmente las marcas por arañazos o pérdida de emulsión. Si no existen fuentes externas para el análisis (making of) es difícil determinar si las imágenes son realmente históricas o no. Como señala García-Reyes (2003) "cualquier manipulación que se hace en la imagen publicitaria tiene una intencionalidad que, en numerosas ocasiones, escapa a la racionalidad de las personas que la observan". Esto es especialmente cierto cuando la manipulación afecta no sólo al significado de la imagen, sino al propio aspecto formal de la misma.

El sonido es tan importante como la imagen. Su manipulación ayuda a reforzar la sensación de estar viendo imágenes antiguas en el espectador. Si bien la publicidad audiovisual se apoya fundamentalmente en la imagen, el sonido tiene un fuerte poder de sugestión. El espectador no entendido no puede discernir si el sonido que acompaña a las imágenes es diegético (el original procedente de las imágenes) o falsamente diegético (por ejemplo, cuando se crea un audio nuevo sobre la imagen de archivo de Marilyn Monroe).

\section{Notas}

1. Asociación para la investigación de los medios de comunicación. Resumen general: octubre 2012-mayo 2013.

2. Según el DRAE, epopeya es un "conjunto de hechos gloriosos dignos de ser cantados épicamente". 
3. La publicidad subliminal es, según la Ley $34 / 1988$, de 11 de noviembre, General de publicidad, la que mediante técnicas de producción de estímulos de intensidades fronterizas con los umbrales de los sentidos o análogas, pueda actuar sobre el público destinatario sin ser conscientemente percibida. La sugestiva se acerca, porque juega con estímulos que provocan sensaciones, pero los estímulos (la marca, el logotipo o los colores de la misma) sí pueden ser percibidos en un visionado minucioso.

4. "El nuevo Mégane muestra leyendas en su niñez". http://www.tvanuncios.com/noticia-1294-el-nuevo-meganemuestra-leyendas-en-su-ninez

\section{Bibliografía}

De-la-Cuadra-De-Colmenares, Elena; López-De-Solís, Iris (2012). "Imágenes de archivo en cine de ficción: cine basado en una historia real". Trípodos, n. 31.

http://www.tripodos.com/index.php/Facultat_Comunicacio_ Blanquerna/article/view/48

García-Reyes, Irene (2003). La mujer, sujeto y objeto de la publicidad en televisión. Madrid: Universidad Complutense de Madrid, Servicio de Publicaciones. ISBN: 84669 21907

http://eprints.ucm.es/4777

González-López, Arturo (2002). Nuevas formas de publicidad en la televisión interactiva. Madrid: Universidad Complutense de Madrid, Servicio de Publicaciones. ISBN: 8466923926 http://eprints.ucm.es/4839

Martínez-Carazo, Piedad-Cristina (2006). "El método de estudio de caso. Estrategia metodológica de la investigación científica". Pensamiento y gestión, n. 20, pp. 165-193.

http://ciruelo.uninorte.edu.co/pdf/pensamiento_ gestion/20/5_El_metodo_de_estudio_de_caso.pdf

Muñoz-Serván, Pilar; Muñoz-Serván, Inmaculada (2001). "Intervención en la familia: estudio de casos". En: Pérez-Serrano, Gloria (ed.). Modelos de investigación cualitativa en educación social y animación sociocultural. Madrid: Narcea, pp. 221-252. ISBN: 9788427713024

http://media.wix.com/ugd/f2803c_dbf7558892bc18793442355d4be06c4b. pdf?dn=Estudio\%2Bde\%2BCasos2.pdf

Ogilvy, David (1990). Anotaciones privadas de David Ogilvy: escritos no publicados sobre dirección y creatividad. Barcelona: Folio. ISBN: 8475831915

Stake, Robert E. (2005). Investigación con estudio de casos. http://danzanet.org/data/2011/10/21/75/file/1322537670i nvestigaci\%C3\%B3n\%20con\%20estudios\%20de\%20casos.pdf

Yin, Robert K. (1999). Investigación sobre estudio de casos. Diseño y método.

http://www.polipub.org/documentos/YIN\%2OROBERT\%20.pdf

\title{
Anuario ThinkEPI 2013
}

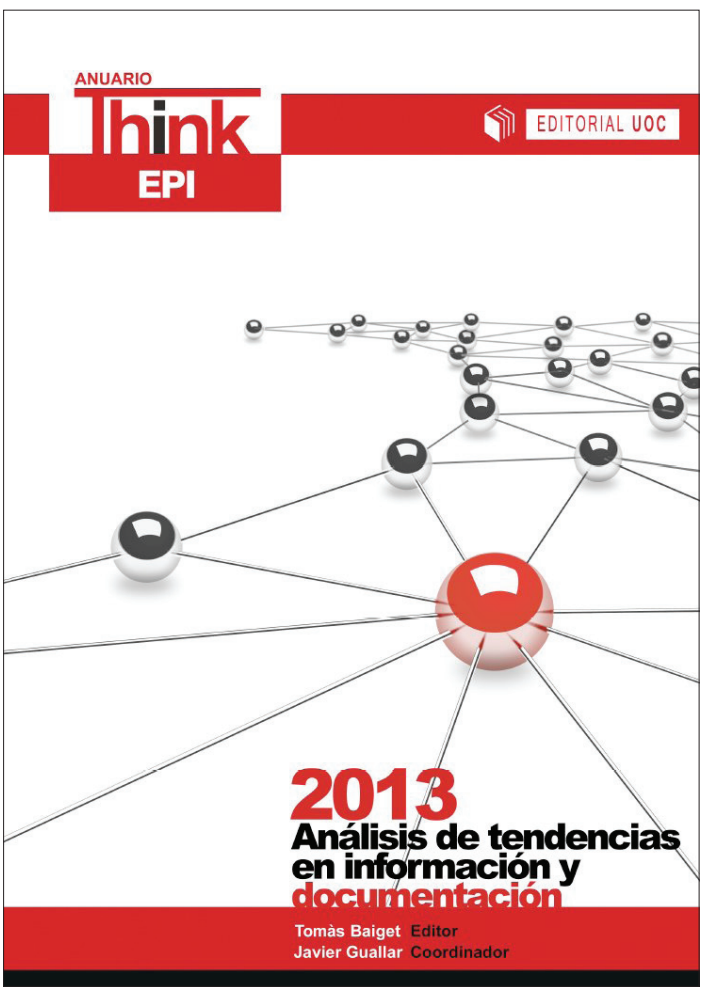

\section{2 páginas de análisis de tendencias en información, documentación y comunicación}

\author{
Formulario de compra: \\ http://www. \\ elprofesionaldelainformacion.com/ \\ suscripciones.php
}

\section{Información y pedidos:}

Isabel Olea

epi.iolea@gmail.com

+34608491521 